\title{
Resolving School Violence: Law, Policy and Advocacy Limitations
}

\author{
Nurwanto Nurwanto ${ }^{1, *}$, Ghoffar Ismail ${ }^{2}$, Farida Amalia ${ }^{3}$
}

\author{
${ }^{1,2,3}$ Department of Islamic Education, Faculty of Islamic Studies, Universitas Muhammadiyah Yogyakarta, Indonesia \\ ${ }^{1}$ School of Education, Western Sydney University, Australia \\ ${ }^{*}$ Corresponding author. Email: nurwanto@umy.ac.id
}

\begin{abstract}
Attention to school violence in Indonesia has expanded through which several laws and policies were produced, especially on children's rights protection. While these legal aspects have been widely developed, studies on their frameworks have been rarely conducted. The current study examines whether the acts or regulations, the governmental policy, and the agency roles are considered adequate in framing school violence. Through the documentary analysis of the laws and the policies, this study reveals that the Indonesian laws are likely to be oriented to respond to a global need for children's safety and to build national trust in children's protection. While the regulations from the Ministry of Women Empowerment and Child Protection, and the Ministry of Health generally emphasize to protect and rehabilitate violence victims, the regulation from the Ministry of Education and Culture tends to establish both preventive and rehabilitative actions. Additionally, the Indonesian Child Protection Commission is placed as the only governmental agency to monitor and to review the fulfillment of children's rights. However, the future need of any other agencies to assist Indonesian schools should not only resolve school violence but also sustain school peace. Implications for practices and future policy research are reviewed.
\end{abstract}

Keywords: School Violence, Laws, Ministry Regulations, Government Policy

\section{INTRODUCTION}

School violence in Indonesia has occurred nationwide at various levels. School violence can be defined as any harmful behaviour either physically or emotionally towards students or school staff [1]. The Child Protection Commission of Indonesia (Komisi Perlindungan Anak Indonesia (KPAI)) has shown behaviours considered as school violence in Indonesia: $51 \%$ physical and sexual violence, and $32 \%$ mass fightings of pupils [2]. In addition, Biro Pusat Statistik (BPS) found that 58 out of 1,655 villages across this country had encountered collective violence among students [3]. Mass violence committed by students has also taken place in big cities such as Jakarta [4], and in relatively small cities such as Surakarta [5], Yogyakarta [6], and Purworejo [7]. Given this violence prevalence, school violence can be drawn as a serious issue thereby urging to shape any immediate as well as long-run response.

In order to provide foundations underpinning school violence management as well as prevention, both relevant legal frameworks and government policy need to be examined. Efforts to deal with school violence have so far been drawn ranging from psychological, sociological to religious approaches. Nonetheless, it is likely that the law and policy which include the acts, ministry regulations and any practical guidance relevant to schools' responses to violence have been paid little attention. The existing relevant laws, regulations, as well as policy, include the Children Protection Act, regulations of such ministries as Education and Culture (MEC), Health $(\mathrm{MH})$, and Women Empowerment and Child Protection (MWECP), and the national strategy for reducing as well as dealing with children's violence. At the level of institution, there has been the Indonesian Child Protection Commission (KPAI), an independent body that monitors the extent of children's rights fulfillment. Another issue is the extent to which any school attempts to follow both the national legal framework and the government policy. Additionally, there should be an institutional response any school can provide to address violence at school or school-directed activities. Thus, the presence of laws and policy needs further understandings for policymakers as well as the front-liners such as principals and teachers.

This article will utilize a variety of perspectives of school violence and peace education to examine the framework of laws, regulations, and policy in Indonesia. The perspectives will provide a discussion of both daily violence relating to physical, temporary, and individual circumstances [8], and systemic violence referring to any institutional rule and its implementation which either make students disengaged with 
their study or violate students' rights [9]. These double scopes of school violence seem to be commensurate with Galtung's notions of both direct violence attributed to physical violence, and indirect violence (re)produced by structural as well as cultural violence $[10,11]$. Cultural violence is any knowledge, belief, and custom pretending to propose as well as legitimizing violence; structural violence is either any rule or power which affects any condition or feeling of being insecure or stigmatized experienced by individuals and the vulnerable such as females, children with special needs, and those with difficulties academically, economically, spiritually as well as socially [12]. In addition, perspectives on peace education that include peace-keeping, peace-making, and peace-building [13, 14] will also be used. Peace-keeping can be defined as an effort to limit existing violence with its impacts while peace-making is approaches and programs to prevent violent behaviours, for instance, through conflict resolution and trauma recovery. Peace-building, on the other hand, is nurturing and sustaining peaceful culture. Thus, various viewpoints of school violence and of peace education become central for critical analysis.

This article provides a review of prior studies on school violence, its management strategies, and the urgency of school reform in dealing with violence. It then explains policy studies and documentary analysis in the methodology section. Its findings are focused on topical aspects of the laws, ministry regulations, and government strategies to address school violence in Indonesia. Furthermore, similarities and differences between the ministry regulations and policy will also be discussed. The last discussion will accentuate the need for school reform relevant to establishing safer schools.

\section{LITERATURE REVIEW}

\subsection{Varieties of School Violence}

Prior studies have placed a lot of emphasis on verbal, emotional, physical, and sexual violence $[4,7,15]$. Jones, et al. [16] further provide an analysis of the evolutionary framework of school violence which includes bullying, physical fighting/weapon usage, drug abuse-directed violence, safe school regulation, murder, and school violence prevention. While the work of Jones, et al. [16] essentially traces previous discussions on what behaviour as well as initiatives categorized as school violence, that of Lassiter and Perry [17] shows systematization of school violence as a behavioural scale. Scale 1 or the bottom scale of violence is verbal expressions such as intimidation. Scale 2 relates to physical behaviours, for instance, fighting. Scale 3 is vandalism, violent gangs, bullying, and any behaviour violating laws. Scale 4 includes rape, sexual harassment, and robbery, and then scale 5 is killing people, suicide, and attacking others with any weapon. This last scale is called 'lethal school violence' [18]. This systematization is likely to demonstrate the extent to which particular violence at school occurs. Both authors also highlight that unawareness of lower scales of violence such as hate speech and intimidation can potentially (re)produce further physical violence and even murder.
While the direct, physical school violence is of great importance for policymakers, researchers, and educational practitioners to formulate solid solutions, there is indirect violence expressed through ideas, utterance, rules, and power of those whose authority is recognized at school. This can be called systemic violence upon which school rules and authority have been constructed either overtly or covertly [19]. Epp and Watkinson [9] argue that systemic violence can lead to educational injustice. It is primarily experienced by students who are intellectually, emotionally, spiritually, or physically vulnerable since they have limited access to knowledge and skills. Galtung [10] puts emphasis on cultural violence that may be hidden behind social beliefs or ideology underlying institutional - school - injustice. Prior research using this Galtung's notion was, for instance, conducted by Guilherme [12] who demonstrates the relationship between cultural, structural, and physical violence. Other studies have shown both cultural and structural violence that have been anchored on corporal punishment and male domination in an African school context [20-22].

Having said the conceptual complexity of school violence, there is a need for a comprehensive perspective that includes both the direct, physical violence, and the indirect, cultural, and structural violence introduced and then elaborated in regulations and strategic policy. However, there is little attention to the Indonesian laws, regulations, government policy, and related institutions to establish school violence prevention or management. While an emphasis on direct, daily school violence has been mostly drawn, there is a gap regarding studies that examine the legal framework from both cultural and structural domains of school violence.

\subsection{Management Strategies of School Violence}

Previous studies on strategies to handle school violence range from policy to philosophy. Saltmarsh, et al. [19] describe three policy models to handle school violence. The first model is applying punishment to students who commit verbal and physical (direct) violence at school. The second model is establishing 'zero-tolerance' through which the third party such as the police will take over the school's roles in handling crime-associated behaviours such as sexual harassment and weapon carrying. The US and Canada have become two examples of countries practicing this policy model. The last model is safer school-promoting programs through which peace education and training and school climate management are considerably established. Saltmarsh, et al. [19] argue that 'zero tolerance' policy could reduce school as the best place for educating young people since students' behavioural issues are not taken over by educationalists. However, what must be acknowledged is that responding to lethal school violence and death-effecting violence [18] is of little sufficiency without any police assistance, considering that, for instance, during 2019, there were approximately 22 weapon-equipped attacks toward American schools [23]. While the first two policy models may focus on an immediate, short-term response to school 
violence, the last model tends to develop a long-term positive response to school violence for school reform. In addition, this third model shapes preventive programs compared to the other two models focusing on the direct handling of violence.

In accordance with both prevention and management strategies of school violence, Guilherme [25] conceptually proposes education prioritizing dialogues. Dialogue model 1 is called a 'symmetrical dialogue' through which two or more people build on equal communication and problem-solving orientations rather than blaming each other. This dialogue is expected to reduce physical and verbal violence which mostly occur among persons objectifying one another. Dialogue model 2 is an 'asymmetrical dialogue' which encourages people to critically think about what they have understood or believed promotes violence, and about whether certain knowledge, science as well as belief leads them to commit violence. Both Guilherme [12] and Standish [11] highlight that uncritical religious understandings can lead to extreme attitudes as a result of a one-sided perspective. Through this critical understanding, people can consider different opinions and provide as well as analyze between facts and assumptions, thereby being habituated with self-reflection instead of taking any information for granted. Moreover, through the asymmetrical dialogue, principals as well as teachers can eliminate cultural violence since they also rethink of whether their schooling processes lead to authoritarian leadership and learning interactions [19]. Next, dialogue model 3 is a public dialogue, a situation where anyone can engage in communication with others to criticize injustice as well as to promote solidarity. As a result, the public sphere can become a channel of understanding, discussing and then criticizing public policy including the school system that may be contradictory to dialogical missions of humankind. Expanding public voices against school violence include the active roles of school executives, communities and government. The extent to which laws, regulations and public policy have involved public voices and participation can be further elaborated.

\subsection{The Need for School Reform}

The extent to which responses to school violence have been established can begin with examining its existing law and regulations but they are of the less sufficiency to look at the complexity of battleground, especially schools, against violence. Having said this perspective, I would argue that there should be a navigated framework of any school that adopts and builds on both school ethos and school climate which are sensitive to school violence. While school ethos refers to philosophies or values that guide a school leader, school staff, students, and parents to establish educational, psychological as well as educational activities, school climate emphasizes any mode as well as the extent of interactions between a teacher and students, or a principal and staff [24] and 'experiences of school life' [25]. Whether both school ethos and school climate are sufficiently linked to a school's response to violent incidents, any school executives' or communities' preparedness can be examined.

Regarding the extent of school readiness to encounter school violence, however, different schools may have different levels of responsivity, and even different individuals within a school may demonstrate different capabilities of handling violence. The work of Twemlow and Sacco [26] shows that there are four psychological phases that school executives as well as communities may experience as violent behaviours emerge at their school: firstly, they may show a denial of the fact that violence has occurred at their school. Secondly, they may show their anger at violent perpetrators rather than their initiatives to build a soft approach to building communication with perpetrators. Thirdly, because both the school executives and communities try to initiate engagement with victims or perpetrators with more proactive rather than reactive responses, they may encounter psychological issues such as depression due to the possible complexity of school violence being handled. Lastly, as a result of the extent of understanding as well as the sustainable programs anchored to proactively respond to school violence, there will be the increased level of acceptance and sensitivity among school staff and communities to school violence. However, Davies [27] argues that, instead of merely psychological readiness, school should be placed as a complex system through which any policy, rule, curriculum and interaction are structured and cultured to accept plurality, seek resolution from potential conflicts and establish responsibility and human rights. Thus, Davies [27] emphasizes structural reform of school while Twemlow and Sacco [26] accentuate personal/psychological processes in encountering school violence. Regardless of these perspectives, the need for school reform responsive to school violence would be institutionally inevitable.

\section{METHODOLOGY}

Because this article aims at analyzing law or regulations and government policy relating to school violence management or prevention, it is then directed as policy analysis. While policy research commonly refers to the study of empirical issues drawn from political commitment and action, and then shape recommendations for public service improvement [28], there are also policy documents per se as the written policy of any government. Because of focusing on policy documents, this article can be considered as a documentary analysis of policy regarding school violence prevention and management. Moreover, any policy of government can be measured with the existing laws or regulations [29]. Given this, the article brings altogether the laws, regulations, and government policy in addressing school violence. It analyses the law of child protection, the Ministry regulations (education, health, and child protection), and other government policies regarding responses to school violence.

In order to obtain the above documents, there have been online sources and ministries' websites available providing any act or regulations to the public. There are several relevant 
official websites explored for this article such as https://www.kemenkumham.go.id/ (the Ministry of Law and Human Rights), https://www.kemdikbud.go.id/ (the Ministry of Education and Culture), https://www.kemenpppa.go.id/ (the Ministry of Women Empowerment and Child Protection), and https://www.kpai.go.id/ (Indonesian Child Protection Commission). After being collected, the data were coded and then categorized by referring to themes that include school violence characteristics, and its prevention as well as management models (thematic analysis). The next data analysis was providing a discussion about the relationship between legal aspects, policy, and school violence prevention as well as management issues in a broader context (international perspectives) since school violence has occurred not only in Indonesia but also in other countries. International perspectives on handling school violence and nurturing peace are also shaped in this article. Therefore, either positive aspects or limitations of the existing laws and policies to address school violence in Indonesia will be discussed through the international lenses.

\section{FINDINGS AND DISCUSSION}

The following findings include legal and policy aspects in Indonesia as a response to children's rights violation as well as school violence, and the roles of Indonesian Child Protection Commission (KPAI), an in dependent body who is responsible of monitoring children's rights fulfillment. Additionally, there will be a discussion between the findings and other studies as well as theories especially cultural violence by Galtung [10], systemic violence by Epp and Watkinson [9], and peace-keeping, peace-making and peacebuilding by, for instance, Harris and Morrison [14] and Bajaj and Hantzopoulos [13].

\subsection{Legal Framework of Addressing School Violence}

\subsubsection{An Evolutionary Concept of Violence towards} Children

Legal references to dealing with school violence in Indonesia can be taken from the Children's Protection Act No. 35/2014 as an amendment of the Act No. 23/2002, which is intended to provide children's legal protection against rights violation due to violence or discrimination. To provide further operational strategies, several ministries especially the MWECP and the MEC have issued specific regulations, that is Regulation No. 11/2011 on guidance for handling violence towards children as victims, and Regulation No. 82/2015 on prevention and management of violence at school. Moreover, all of these acts and regulations can be regarded as the details of Indonesia's Constitution, UUD 1945 (amended) article 28I on protection and advocacy of citizens' rights for life, freedom of thought, religion, being free from torture and slavery, and being recognized as individuals before law. Additionally, the former President of the Republic of Indonesia ratified the international convention of children's rights through Regulation No. 36/1990 on ratification of Convention on the Rights of the Child. Thus, legal protection for children's rights is of sufficiency as guidance for those responsible of and concerned with school violence.

While violence against children in the Act and Regulations has been clarified with specific definitions, the violence characteristics accommodated in the rules are virtually different from one rule to another. Act No. 35/2014 defines violence against children as

$$
\begin{aligned}
& \text {... every behaviour exposed to children which results } \\
& \text { in misery or suffering, either physically, } \\
& \text { psychologically or sexually, or/and ignorance, } \\
& \text { including threats to conduct any behaviour, } \\
& \text { imposition, or freedom appropriation against law } \\
& \text { (article 1, point 15a). }
\end{aligned}
$$

The conceptual framework in the Act covers not only physical and sexual violence called 'direct violence' [10] but also psychological/emotional violence (indirect violence) and social ignorance to children (structural violence). Term 'ignorance' (penelantaran) included in this Act as a part of children's violence can be seen as novel adaptation to an evolutionary concept of violence as discussed in the discourse of school violence [16]. Comparatively speaking, the MEC Regulation No. 82/2015 includes cyber-bullying dan violence through a textbook (article 1 point 1 ) informing, for instance, violence by males is considered as less problematic than violence by females. Written violence shown in a textbook can be categorized as symbolic violence [30] by which hatred and domination may be illustrated through written narratives. However, this Regulation does not explicitly include ignorance in the provided definition. Even if the definition of children violence in the Act and the Regulation can be complementary to each other, incorporating the concept 'ignorance' into the Regulation is likely to be essential. The argument is that school as a public institution is potentially violent as called 'systemic violence' [9] as ignoring equal and just services towards pupils irrespective of their different circumstances, either intellectually, economically, religiously or socially. Furthermore, the WECP Regulation No. 2/2011 includes potential perpetrators, that is the parties which have an authority and are responsible of children such as parents/caregivers and teachers. The incorporation of these potential violent perpetrators shows that the Regulation is likely to open public mindsets where violence to children can be behaved by such close figures of the children.

\subsubsection{Responses to Violence Against Children: Prevention or Control?}

The existing law and regulations have provided strategies of handling violence to children ranging from preventive to control efforts. The Act No. 35/2014, for example, highlights prevention and direct handling of child victims exposed to physical and psychological violence (article 59), sexual violence (article 69A) and terrorism (article 69B) through socialization of the law/regulations, supervision of their implementation, values education, 
punishment for perpetrators, and counselling and rehabilitation of violent victims. Likewise, the WECP Regulation No. 11/2011 guides any party to handle victims by providing initial identification, health rehabilitation, social rehabilitation, advocacy/law assistance, return to home and social integration (article 1 point 1). Due to the need of various sectors in handling victims or perpetrators, the government issued the Regulation No. 59/2019 asserting that children's rights protection can be collaboratively responded by multiple-sectors of the government which include health, law, education, counselling units and any community concerned with children's rights fulfillment. Thus, efforts to both prevent and handle violence to children need greater involvement of relevant sectors.

Furthermore, the MEC Regulation No. 82/2015 differentiates between violence prevention and control. Violence prevention is defined as an action/approach/process attempted to encourage people not to perpetrate violence (article 1 point 4) whereas violence control is intended to handle violence occurring at school environment (article 1 point 5). This legal framework is in line with violence handling known as peace-making through which a public space is attempted to be free from violence or discrimination, and peace-keeping whose main goal is to keep people resilient and under-controlled amid violence [14, 31]. However, peace-building, an effort to establish and sustain peaceful values, is implicitly absent from this Regulation since, maybe, it is focused on fighting against violence which has been prevalent and exposed to many Indonesian teenagers in the last few years $[2,5,32]$.

The MEC Regulation in greater details elaborates several strategies in both violence prevention and handling at school. Article 8 of this Regulation lists prevention strategies as follow: 1) establishing school environment free from violence; 2) creating safe and joyful environment; 3) keeping students' health; 4) providing reports to parents if there are early violent incidents; 5) issuing an SOP (standard operational procedure) of violence prevention; 6) informing the SOP to stakeholders; 7) building cooperation with other institutions such as counseling units and religious groups; 8) establishing a violence prevention team approved by every principal; and 9) providing complaint services. Additionally, at the provincial level, there must be a school violence prevention team which builds network and cooperation with a team at the school level. Furthermore, article 10 emphasizes violence management at school which includes 1) early rescuing a victim; 2) informing parents; 3) investigating violent incidents; 4) proportionally following up violent cases; 5) establishing coordination with other appropriate institutions; 6) ensuring students' learning continuity; 7) facilitating students to obtain any law protection; 8) providing rehabilitation; and 9) providing a report to the Department of Education and police regarding fatal incidents.
These strategies for violence prevention and handling at school can be examined. Firstly, violence prevention efforts need greater attention and participation from all school elements. The problem is that if violence occurring at school is only considered as a responsibility of the school violence prevention team. Secondly, there can an issue regarding an information flow of violent cases. For instance, if there is violence committed by a principal, how would such information be followed up towards parents as information as well as to the school team because the principal by law must be a member of the team (Article 8)? Thus, every school or violence prevention team needs collaborative but fair actions. Thirdly, the violence management strategies are mostly related to responses to physical violence at school. Fourthly, punishment approaches seem to be dominant as explained that sanction will be applied to either students, teachers or school institutionally if perpetrating or perpetuating violence (Article 11 and 12). As a result of involving police in approaching perpetrators, either punishment or zero tolerance approach [19] may be commonly practiced.

Meanwhile, the Ministry of Health (MH) has generally accentuated health services to violence victims even if, to a smaller extent, counseling and family empowerment are also offered. There are at least two health services provided for victims due to physical violence, that is hospitals located at every district and Puskesmas, a health unit at subdistrict levels [33]. Therefore, schools could coordinate with these health services regarding their responses to victims with physically violent incidents.

\subsection{National Policy towards School Violence}

National policy here can be regarded as any official strategy or plan issued by the central government and its ministries, particularly concerning their responses to prevent as well as handle violence which occurs at school environment so that children's rights can be protected. The national policy can be linked to the existing acts/regulations [29], and becomes an operational bridge between those rules and real programs. There are three policy documents explored in this article concerning national policy of children's protection as well as responses to violence to children, namely National Action Plan for Children's Protection (NAPCP) 2015-2019, National Strategies of Violence Reduction towards Children (NSVRC) 2016-2020, and Practical Guidance of Children Friendly School (PGCFS) (2015).

\subsubsection{Action Plans for Children's Safety}

Through the Ministry/Board of National Development Planning, the government has decreed NAPCP 2015-2019 focusing on children's rights protection. In this document, any violence prevention or management programs should be evidence-based, thereby adequately addressing children's rights violation. There are two national strategies to protect children's right (p.4). Firstly, there should be early detection 
to children's rights violation and then established social protection through, for instance, the vulnerable people's identification, families' roles strengthening, reproduction health curriculum and skill-based curriculum development for youths. Secondly, community capacity-building are needed for parents, religious leaders, professionals, volunteers and social workers, concerning their capacities in parenting, free-from-violence-school environment building, children's skills development, and parenting development beyond a nuclear family (extended families, communities and foster-parents) (p.31).

Regarding the two action plans, I would note some significant issues. Firstly, besides involving a great member of families and communities, the document recommends the need to enhance youths' skills to generate economy. It may be influenced by a notion stating that teenagers' earlier engagement with productive skills would compensate their overloaded energy used for destructive or violent behaviours $[5,34]$. Secondly, this action plan is unlikely to merely propose peace-keeping aimed at protecting victims as well as localizing violent perpetrators, and peace-making practiced to reduce violent behaviours, as asserted in the Act No. 35/2014 and the MEC Regulation No. 82/2015. Rather, it emphasizes peace-building through greater positive parenting roles where a nuclear family, an extended family, school and communities are shaped as a preventive space of teenagers' violence tendency. Even if the parenting system is not explained in detail in the document, it indicates that any environment or space, for instance, families and schools where teenagers build interactions with others should be responsibly treated.

\subsubsection{Diminishing Violence towards Children}

The Ministry of Women Empowerment and Children Protection (MWECP) proposes NSVRC 2016-2020 which includes: 1) legislation and policy implementation oriented to protect children from any violence; 2) alteration of social norms and cultures where violence has been ignored, accepted as well as legalized; 3) a parenting system by which safe and loving relationship between parents/caregivers and children are highly supported to prevent violence; 4) children's life skills and resilience improvement for violence prevention and a support of children's basic education; 5) availability of affordable and quality services for violence victims, perpetrators, and children at risk; and 6) establishment of data quality and its supporting evidence regarding violence towards children (pp. 25-26). The violence prevention-oriented national strategies are shown in point 2), 3 ) and 4) while dealing with victims is mentioned in point 1), 5) and 6). Some of the NSVRC 2016-2020 seems to have similarities with several plans proposed by the NACP 20152019 regarding parenting approaches and children's life skills. Thus, intersectoral communication among ministries and related institutions are needed for resolving school violence.

\subsubsection{Child Friendly School}

Related to the urgency of peace-building at school, the MWECP has produced the PGCFS in 2015. The children's friendly schools program can be considered as a long-term violence prevention action and be relevant to safer school programs [19], an effort to alter school cultures to fit positive peace [35] where cooperation and peace can be sustained. Child friendly school (CFS) is defined as

Any formal, non-formal and informal educational institution, which is safe, hygienic and healthy, caring, and environment-friendly, able to guarantee, fulfil, respect children's rights, and [able to] protect children from violence, discrimination and other maltreatment, and supports children's participation especially in planning, policy, instruction, controlling, and complaint mechanism regarding rights fulfillment and children's protection in education (the MWECP Regulation No. 11/2011, article 1 point 3 ).

As a national program that involves intersectoral institutions, the child friendly school (CFS) has been developed as well as sustained at any level including some ministries, governmental bodies and communities. Other local programs that have been claimed to have relevancy to the CFS are as follows: Sekolah Adiwiyata/Adiwiyata School (the Ministry of Environment and the Ministry of Education), Sekolah/Madrasah Aman Bencana/Disaster Free School (National Board of Disaster Management), Sekolah Inklusif/Inclusive School (the Ministry of Education), Sekolah Hebat/Amazing School (the Ministry of Education), Sekolah Dasar Bersih Sehat/Hygienic and Healthy School (the Ministry of Education), Lingkungan Inklusif Rapat Pembelajaran/Inclusive Environment Closed to Learning (UNESCO), Children Friendly School (UNICEF), Sekolah Sehat/Healthy School (the Ministry of Health), Usaha Kesehatan Sekolah/School Health Unit (the Ministry of Health), 'Pangan Jajan' Anak Sekolah/Snacks for Pupils (BPOM), Warung Kejujuran/Honest Shop (Corruption Eradication Commission), Sekolah Bebas Napza/Narcotics Free School (National Board of Narcotics), Pesantren Ramah Anak/Children Friendly Islamic Boarding School (the Ministry of Religious Affairs), Pendidikan Anak Merdeka/Free Children Education, Komunitas Belajar Mandiri/Independent Learning Community, Sekolah Kehidupan 'Qoryah Thoyyibah'/Life School 'Great Village', and Indonesia Herritage Foundation (PGCFS, 2015, p.8). Regarding the variety of CFS-related programs, the concept of peaceful or safer schools includes not only their capacity to reduce violence but also their greater attention to internalize positive attitudes related to environment, social plurality, food consumption and industry, religious involvement and community engagement. 


\subsection{Roles and Contributions of the Indonesian Child Protection Commission}

One of the independent bodies mandated in the Act No. 35/2014 on children protection is the Indonesian Child Protection Commission (KPAI). Even if this commission is initiated by the government, its members must come from different backgrounds such as bureaucrats, religious/community leaders, social workers, professionals and entrepreneurs (article 75 point 2). Their roles focus on monitoring, researching, collecting complaints, mediating, establishing intersectoral institutions and reporting legal cases, related to children's rights violation (article 76). To detail its roles, this institution sets out the National Strategies 2015-2019 as follows:

developing monitoring models and instruments integrated to children rights monitoring networks; analyzing policies and laws concerning children's rights protection and their implementation and proposing ideas to improve public policy for children's rights protection; developing data and information system in monitoring children's rights implementation; enhancing complaint services for societies relevant to children's rights violation; improving quality mediation services supported with certified mediators; establishing strategic cooperation and partnership with stakeholders related to children's rights monitoring; improving quantity and quality of public reports relevant to children's rights protection ( $\mathrm{p} .23)$.

According to KPAI [2], there was an increase of children's right violation annually where the data was obtained from the direct monitoring to 14 provinces, online services and letters posted to this commission. Additionally, there were almost 5,000 reported cases in 2018 compared to approximately 2,000 cases in 2011 [2]. The data demonstrates that violent incidents as well as children's rights issues have doubled in numbers and there have flourished public hopes towards this commission to sustain their roles of monitoring and proposing advocacy to children's rights fulfillment. Given this actual advantage, this body needs to establish a follow up of every monitored and reported case. Besides providing advocacy followed up to relevant legal institutions, its roles highly need to provide recommendations for either specific educational institutions or communities to be involved in proactive approaches towards both victims and perpetrators. While punitive approaches may be undertaken by law enforcers, either schools, families or communities can be supported, for instance, to keep applying peace-making programs such as conflict resolution activities (e.g. mediation and dialogues) and post-trauma problem solving, and peacebuilding programs by culturing positive school climate which is adequate for supporting children friendly schools.

\subsection{Discussion: Sufficiency of Approaching School Violence and Urgency of Establishing School As A Responsible System}

Regarding the definition of violence towards children, there are similarities and differences as explained by legal documents. Overall, the laws/regulations have a similarity to recognize the categories of physical, sexual and psychological violence. The difference is that the Child Protection Act No. 35/2014 or No. 23/2002 adds ignorance as violence, the MEC Regulation No. 82/2015 includes cyber-bullying and the MWECP Regulation No. 11/2011 includes ignorance and possible perpetrators committed by teachers, staff and parents. These findings are relevant to prior studies of direct or physical violence such as interpersonal and mass fighting and student gangs-led violence in some regions in Indonesia [4-7, 32] and global trends of school violence [15] to which either government or societies need to pay greater attention. Furthermore, the MEC Regulation includes potential violence exposure through schools' textbooks known as symbolic violence [30] while the Child Protection Act addresses social ignorance as a part of cultural and structural violence [10]. The variety of violence drawn in the legal documents indicates that, firstly, any form of violence is not acceptable at school. Secondly, as if the documents are in a process of accommodating an evolutionary concept of school violence [16] ranging from physical, symbolic to systemic violence. However, with the adaptation to various characteristics of violence, either school and other parties need greater capacities for violence prevention and management. While physical/direct violence and its victims can be easily recognized, identifying the presence of cultural/structural violence at school may be uneasy. The work of Kwon, et al. [36] shows that verbal and physical violence by male student gangs can be sensibly addressed but cultural violence behind some studied Korean schools cannot be easily investigated. Despite this complexity, the comprehensive understanding of potential violence at school can lead to a perspective of school as a dynamic system where pupils should be safe, either physically, psychologically, culturally or socially.

In terms of school violence prevention or management, every legal document tends to demonstrate different emphasis. The Child Protection Act provides strategies to protect children's rights as well as to handle violence to children, namely law/regulation socialization, monitoring its implementation, punishment/sanction to perpetrators, values education, and rehabilitation and counseling for victims. In dealing with violence victims, the MWECP Regulation recommends any party to ensure that they, either personally or assisted by others, can report violent incidents to the Women and Children's Service Unit at every subdistrict then followed up to the local police. At this stage, the reported victims will be identified and, if needed, they will obtain health, social or legal rehabilitation, and then be returned home and integrated to their communities. In addition, the MEC Regulation asserts any effort to handle, reduce and, to some extent, prevent the 
level of violence where, for instance, every school must ensure to build its environment free from violence, establish a violence prevention team, and the team then ensure to build communication with parents and other relevant parties and follow up any violent incident. In practice, maybe this Regulation will be variously interpreted regarding, for example, how to create a non-violent school. In America, due to rampant gun violence, a 'zero tolerance' approach has been largely applied [9] and school property has been equipped with a CCTV and metal detectors [37]. Related to deadly violence in Indonesia, the Regulation may also undertake this 'zero tolerance' practice due to police involvement. These findings indicate that greater attention will be drawn to direct (physical, verbal and sexual) violence because it is 'on the surface' for sensible investigation whereas peace-building, an effort to sustain peaceful culture and system, may be virtually neglected. Therefore, the children friendly school programs, as the Ministry of WECP issued, could catalyze further school peace-oriented policy since school is an educational arena where pupils need greater attention to education than punishment [17].

Meanwhile, the government policies which include NAPCP 2015-2019, NSVRC 2016-2020, and PGCFS 2015 show national strategies with some tendencies. Firstly, NAPCP and NSVRC can be synchronized with the Children Protection Act, and the MWECP and MEC Regulation, aimed at rescuing violence victims and localizing violent impacts (peace-keeping) and reducing escalation of violent behaviours (peace-making) by empowering parents', staff and teachers' abilities in attempting to prevent the reemergence of previous violence. Secondly, different from the legal framework and other policies, the children friendly school (CFS) has been the only policy which enables peacebuilding to be sustained. This policy can be intertwined with positive parenting programs encouraged to be implemented at the level of school, community and both nuclear and extended family (NAPCP 2015-2019). Peace-building and positive parenting are highly needed to maintain school climate where educational relationship between teachers, staff, students and parents can elevate [24] thereby enhancing students' learning quality.

In regard to the roles of the KPAI, and the need for school reform in responding to violence and discrimination, there are some related issues for discussions. Firstly, the KPAI solely provides services of monitoring, information collection, and advocacy related to children' rights violation. I would argue that its roles need to intensify cooperation with any other relevant institutions - as stated in its strategic plan no. 6such as school, in particular, in order to optimize the roles of schools' human resources through critical and public dialogues [12] and problem-solving conducted also with parents in which violence attempts to be resolved. Secondly, adaptation to the CFS policy seems to need the establishment of school as a complex system [27] in which plurality is placed as potentials for cooperation, any conflict is responded with communication and problem-solving, any information channel is utilized for peace campaign, and both responsibilities and rights are respected. Therefore, responses to violence at school should not be separated from an effort of establishing a systemic, responsible, and sustainable school.

\section{CONCLUSION}

As well as becoming a global challenge, school violence has reoriented laws and regulations of contemporary Indonesia. To date, this country has had the legal framework and the government policy directly connected with efforts of protecting children's rights in general, and of dealing with violence at school in particular. Endeavours to handle children as victims of violent behaviours or discrimination can be found in the Children Protection Act No. 35/2014 or 23/2002 and the Ministry of WECP No. 11/2011, and health services for victims have been issued by the Ministry of Health's $(\mathrm{MH})$ regulations. Additionally, the presence of Indonesian Child Protection Commission (KPAI) stated in the Act is to monitor the extent to which children's rights have been fulfilled by any institution, family or community. Furthermore, the MEC Regulation No. 82/2015 not only provides an explanation of handling violence victims at school but also urges every school to establish a violence prevention team, which can be coordinated with a similar team at every level district. The central government also issues strategic policies such as NAPCP 2015-2019, and NSVRC 2016-2020 aimed at reducing violence and discrimination escalation, and PGCFS 2015 established to guide every school in nurturing safe environment for pupils and school's community.

Because the primary issue is violence at school, every school should focus not only the short-term programs to handle or reduce violence, but also the long-term peacebuilding programs such as democratic teacher-student relationship. Thus, a number of the existing laws/regulations/policies, and such institutions as the KPAI and the violence prevention team at school may be placed as a temporary scenario of handling or reducing school violence. This standpoint may have benefitted in rescuing emergency due to physical violence exposure. On the other hand, the regulations' trajectory seems to have a limitation to advocate the sustainability of a safer school, both culturally and structurally. In the long run, every school needs greater attention to a friendly and peaceful ethos, problem-solving orientation, and environment governance sensitive to students' need for rights and responsibility fulfillment.

As a documentary study of the laws and policies on school violence responses, this article may have limitations since it only explores written sources such as the Acts, the Ministry Regulations and the government strategic plans. Future studies can be emphasized on an empirical analysis of the existing documents so that practical contexts can be 
generated for further recommendations for both policy makers and educational practitioners.

\section{ACKNOWLEDGMENT}

The authors would like to thank the Board of Research, Publication and Community Development (LP3M), Universitas Muhammadiyah Yogyakarta, Indonesia, which funded the research project (Reference Number: 034/PEN$\mathrm{LP} 3 \mathrm{M} / \mathrm{I} / 2020$ ), and this article is a part of this project.

\section{REFERENCES}

[1] R. Berkowitz et al., "School Violence," in Oxford Research Encyclopedia of Education, ed. Oxford: Oxford University Press, 2019, pp. 1-20.

[2] KPAI, Laporan Kinerja KPAI. Jakarta: KPAI, 2018.

[3] BPS, Statistik Kriminal 2014. Jakarta: BPS, 2014.

[4] H. M. Saad, Perkelahian Pelajar: Potret Siswa SMU di DKI Jakarta. Yogyakarta: Galangpress Group, 2003.

[5] P. Nilan, A. Demartoto, and A. Wibowo, "Young men and peer fighting in Solo, Indonesia," Men and Masculinities, vol. 14, no. 4, pp. 470-490, 2011.

[6] H. A. Kadir, "School gangs of Yogyakarta: Mass fighting strategies and masculine charisma in the city of students," The Asia Pacific Journal of Anthropology, vol. 13, no. 4, pp. 352-365, 2012.

[7] M. Djamal, Fenomena Kekerasan di Sekolah. Yogyakarta: Pustaka Pelajar, 2016.

[8] S. E. Daly, Everyday School Violence: An Educator's Guide to Safer Schools. London: Rowman \& Littlefield, 2018.

[9] J. R. Epp and A. M. Watkinson, Systemic Violence in Education: Promise Broken. New York: SUNY Press, 1997.

[10] J. Galtung, "Cultural violence," Journal of Peace Research, vol. 27, no. 3, pp. 291-305, 1990.

[11] K. Standish, Cultural Violence in the Classroom: Peace, Conflict and Education in Israel. UK: Cambridge Scholars Publishing, 2015.

[12] A. Guilherme, "Understanding conflict resolution philosophically in a school setting: three different kinds of violence and dialogue," Journal of Peace Education, vol. 14, no. 2, pp. 215-234, 2017.

[13] M. Bajaj and M. Hantzopoulos, Peace education: International Perspectives. London: Bloomsbury Publishing, 2016.

[14] I. M. Harris and M. L. Morrison, Peace Education. USA: McFarland, 2012.

[15] UNESCO, School Violence and Bullying: Global Status and Trends, Drivers and Consequences. France: UNESCO, 2018.

[16] S. N. Jones, R. Waite, and P. T. Clements, "An evolutionary concept analysis of school violence: from bullying to death," Journal of Forensic Nursing, vol. 8, no. 1, pp. 4-12, 2012.

[17] W. L. Lassiter and D. C. Perry, Preventing Violence and Crime in America's Schools: From Put-Downs to LockDowns: From Put-Downs to Lock-Downs. USA: Praeger, 2009.

[18] J. A. Daniels and M. C. Bradley, Preventing Lethal School Violence. London: Springer Science \& Business Media, 2011.
[19] S. Saltmarsh, K. Robinson, and C. Davies, Rethinking School Violence: Theory, Gender, Context. London: Palgrave Macmillan, 2012.

[20] L. Davies, "Educating against extremism: Towards a critical politicisation of young people," International Review of Education, vol. 55, no. 2-3, pp. 183-203, 2009.

[21] C. Harber, "School, Violence and Peace Education," in Encyclopedia of Peace Education, ed. Columbia: Columbia University, 2008.

[22] C. Harber, Toxic Schooling: How Schools Became Worse. England: Educational Heretics Press, 2009.

[23] E. Wolfe and C. Walker, "In 46 weeks this year, there have been 45 school shootings," in $C N N$, ed, 2019.

[24] D. Glover and M. Coleman, "School culture, climate and ethos: interchangeable or distinctive concepts?," Journal of In-service Education, vol. 31, no. 2, pp. 251-272, 2005.

[25] V. Grazia and L. Molinari, "School climate multidimensionality and measurement: A systematic literature review," Research Papers in Education, pp. 1-27, 2020.

[26] S. W. Twemlow and F. C. Sacco, Preventing Bullying and School Violence. USA: American Psychiatric Publishing, 2012.

[27] L. Davies, "Education and violent extremism: Insights from complexity theory," Education and Conflict Review, vol. 2, pp. 76-80, 2019.

[28] R. H. Heck, Studying Educational and Social policy: Theoretical Concepts and Research Methods. London: Routledge, 2004.

[29] S. Knotter, R. De Lobel, L. Tsipouri, and V. Stenius, Diversity Research and Policy: A Multidisciplinary Exploration. Amsterdam: Amsterdam University Press, 2011.

[30] J. Buckworth, "Symbolic violence in teacher education: embracing cultural diversity or cultural discrimination?," Asia-Pacific Journal of Teacher Education, vol. 47, no. 3, pp. 309-321, 2019.

[31] I. M. Harris, "Peace-building responses to school violence," NASSP Bulletin, vol. 84, no. 614, pp. 5-24, 2000.

[32] I. Rifai, "Violence in an Urban Indonesian High School," $\mathrm{PhD}$, Education, University of Leeds, Leeds, 2016.

[33] Kemenkes, Kekerasan Terhadap Anak dan Remaja. Jakarta: Kementerian Kesehatan RI, 2018.

[34] P. Nilan, "The gang, violence and the life course for Indonesian male youth," in Paper for XVII World Congress of Sociology (ISA-RC 34), Gothenburg, Sweden, 2010, pp. 11-17.

[35] IEP, Global Peace Index: Measuring Peace in a Complex World. Sydney: Institute for Economics and Peace, 2018.

[36] S. Kwon, D. I. Walker, and K. Kristjánsson, "Shining light into dark shadows of violence and learned helplessness: peace education in South Korean schools," Journal of Peace Education, vol. 15, no. 1, pp. 24-47, 2018.

[37] M. J. Cuellar, "School safety strategies and their effects on the occurrence of school-based violence in US high schools: An exploratory study," Journal of School Violence, vol. 17, no. 1, pp. 28-45, 2018. 